\title{
Avosidade: Visões de avós e de seus netos no período da infância
}

\author{
Grandparenthood: Viewpoints of grandmothersand their grandchildren during childhood
}

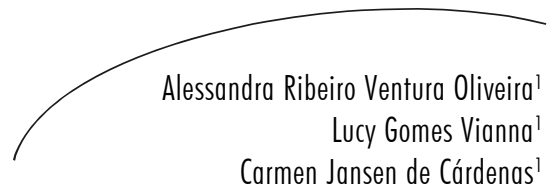

Resumo

O papel do idoso tem sofrido modificações, tanto no âmbito social quanto no familiar. Aumentaram o número de avós e o número de anos que as pessoas vivem como avós. A avosidade, definida como laço de parentesco, está intimamente ligada às funções materna e paterna, das quais, entretanto, se diferencia, exercendo papel determinante na formação do sujeito. O objetivo deste trabalho foi avaliar a relação entre avós e netos no período da infância, de acordo com a percepção de avós e de seus netos. Foram realizadas 17 entrevistas semiestruturadas com avós e seus netos. Os resultados foram analisados e categorizados utilzando-se o software ALCESTE, o qual realiza automaticamente análise quantitativa de dados textuais. O estudo revelou presença significativa de intergeracionalidade na visão das avós, representada pelas palavras mais frequentes em ordem decrescente: avó, netos e pai. A classe 1 ( $34,45 \%)$, mostrou o quanto a avosidade é significativa, representada por atividades realizadas com os netos; na classe 2 (42,86\%), verificou-se o quanto as avós se sentiram bem realizando essas atividades; na classe 3 (22,69\%), foi visualizada a visão das avós sobre a velhice. Foram formados dois eixos: o primeiro, constituído pelas classes 1 e 2 (relação intergeracional), e o segundo, pela classe 3 (velhice). A relação obtida entre as classes 1 e 2 foi de 0,4, e entre os eixos 1 e 2 foi 0 . Para análise dos discursos dos netos, revelaram-se as categorias e subcategorias, respectivamente: benefício - diversão e afeto; sentimento - orgulho e diferença; significado da velhice - desconhecido e previsível. $\mathrm{Na}$ categoria benefício, os dados obtidos indicaram que os netos ou netas sentiam-se alegres e satisfeitos quando realizavam determinadas atividades com as avós. Além disso, valorizavam o carinho dispensado por elas. Na categoria sentimento, os netos evidenciaram as qualidades pessoais de suas avós, construindo formas diferentes de relações entre avós e netos. Por fim, na categoria significado da velhice, alguns netos mostraram desconhecimento sobre o significado do termo, enquanto outros possuíam em suas mentes uma imagem de como será a sua velhice. No presente estudo, pode-se concluir que avós idosas mantêm forte relação de proximidade vivenciada com seus netos no período da infância, o que é confirmado e reconhecido por seus netos. 1 Universidade Católica de Brasília. Programa de Pós-graduação em Gerontologia. Brasília, DF,
Brasil.

Correspondência / Correspondence

Alessandra Ribeiro Ventura Oliveira

Universidade Católica de Brasília - Campus Universitário II

SGAN 916 Módulo B

70790-160 Brasília, DF, Brasil

E-mail: a.oliveira53@gmail.com

Palavras-chave: Relações Intergeracionais. Avós.

Netos. Avosidade. 


\section{Abstract}

The role of the elderly has changed, both in society and within the family. The number of grandparents has been growing, as well the time they live as grandparents. Grandparenthood is a bond between relatives, linking mother and father functions in spite of their differences, playing an important role in the person's development. This study aimes to analyze the relationship between grandmothers and grandchildren during childhood, according to the perception of grandmothers and grandchildren. We conducted 17 structured surveys with the grandmothers and their grandchildren. The results were analyzed trough the ALCESTE software, which performs an automatic quantitative study of text information. The study revealed a significant presence of intergenerational relationship in grandmothers' viewpoint, represented by the most common words, in decreasing order: grandmother, grandchildren and dad. Class $1(34,45 \%)$ showed how significantly was grandparenthood represented for the activities performed with grandchildren; Class $2(42,86 \%)$, how grandmothers felt carrying through such activities; and Class 3 (22,69\%) showed the elderly's view about old age. Two lines were created, the first called intergenerational relationship (Classes 1 and 2) and the second called old age (Class 3). The relation between classes 1 and 2 was 0,4 and between the lines 1 and 2 was 0 . The analysis of grandchildren's speeches revealed categories and subcategories, respectively: benefit - entertainment and affection; feeling - proud and difference; meaning of old age unknown and predictable. In the benefit category, results indicated that the grandsons or granddaughters felt happy and pleased when they performed activities with their grandmothers. Beyond this, they used to value the affection offered by the grandmothers. In the feeling category, the grandchildren showed the personal qualities of their grandmothers. They built different kinds of relations between grandparents and grandchildren. In the meaning of old age category, some grandchildren did not know the meaning of the term, whereas others kept in mind how their old age will be in the future. This study concluded that elderly grandmothers have a close relationship with their grandchildren during childhood, and this relation has been confirmed and recognized by their grandchildren.
Key words:

Intergenerational

Relationship.

Grandmother.

Grandchildren.

Grandparenthood.

\section{INTRODUÇÃO}

A arte de ser avó é vista como aspecto privilegiado da habilidade de ser pais de filhos adultos, partilhando ideias e experiências dentro da nova condição de simetria que os filhos atingem ao se tornarem pai ${ }^{1}$. Ao aproximar gerações, são quebradas barreiras, eliminados preconceitos e vencidas discriminações ${ }^{2}$.

As relações dos netos com seus avós constituem uma linha de investigação na qual se torna necessário abordar perspectiva bidirecional e interativa, pois cada questão que se discute depende da interação de ambas perspectivas ${ }^{3}$. A importância da mutualidade da relação entre avós e netos foi reconhecida sobretudo durante a década de 80 e, desde então, o interesse sobre a avosidade cresceu consideravelmente. Dentre os fatores que contribuíram para esta situação, está o aumento na expectativa de vida, o que tem levado a maior tempo de permanência dos indivíduos na função de avós.

O século XXI será o século dos avós. Entre os americanos, cerca de $50 \%$ tornam-se avós entre 49 e 53 anos, passando de 30 a 40 anos exercendo este papel. Na França, cerca de $80 \%$ das avós têm mais de 65 anos e $50 \%$ delas tornar-se-ão bisavós, enquanto em torno de $20 \%$ das mulheres com mais de 80 anos já são tataravós. Na Inglaterra, quase metade da população tem netos, sendo que $25 \%$ do grupo são os principais cuidadores dessas crianças, passando, em média, seis horas por semana substituindo os pais ${ }^{1}$.

No Brasil, quanto mais elevado o número de filhos, maior é a chance de a mulher acima de 60 anos ter filhos e netos residindo em sua casa. Em 2000 , os netos representavam cerca de $14 \%$ dos 
membros nas famílias de idosos, assim como $2 \%$ nas famílias com idosos 5 . Um número menor de netos potenciais entra em relação com um número crescente de avós, que estão cada vez mais jovens, tornando a idade uma variável isolada e conflituosa na relação entre avós e netos ${ }^{6}$.

$\mathrm{O}$ acesso dos netos aos avós, no período da infância, é controlado pelos pais, principalmente para aqueles que não moram próximos ${ }^{7}$. Nesse período, o relacionamento entre avós e netos pode ser marcado pelo prazer e brincadeiras que ocorrem, sendo que, à medida que os netos crescem, outros significados poderão adquirir relevância ${ }^{7}$.

A velhice é um conceito multifatorial, contemplado não apenas por transformações biológicas e cronológicas, mas também por questões sociais e culturais. Ao estabelecer um paralelo entre a velhice e a infância, é possível resgatar lembranças sobre velhos ou sobre a velhice que ainda não foram vivenciadas ${ }^{8}$. Assim, os netos exercem fundamental importância na vida dos avós e o contato entre avós e netos pode ser essencial para as pessoas que estão envelhecendo?.

O estudo atual focalizou a temática da avosidade, definida como laço de parentesco entre avós e netos, estando os últimos no período da infância ${ }^{10}$. Assim, avosidade é tema que cria um elo entre a pediatria e a gerontologia.

\section{MATERIAL E MÉTODOS}

Utilizou-se método qualitativo, sendo a amostra de 17 avós e seus respectivos netos recrutada de dois ambulatórios de Pediatria de responsabilidade da autora principal, sendo um deles particular e o outro em hospital da rede pública. Todos os entrevistados eram domiciliados no Distrito Federal. As avós estudadas acompanharam seus netos às consultas pediátricas realizadas nos ambulatórios citados.

Foram critérios de inclusão: avós com idade $\geq 60$ anos, possuindo um ou mais netos com idade de 6 a 12 anos; cognição normal; consentimento por escrito em participar da pesquisa, das avós e dos responsáveis pelas crianças a serem entrevistadas.

Realizou-se contato com a avó participante e seu(s) neto(s) durante a consulta pediátrica. Foram fornecidos esclarecimentos às avós e aos responsáveis pelas crianças a serem entrevistadas sobre o objetivo da pesquisa, o que seria abordado nas entrevistas e o tipo de participação que seria necessária. As entrevistas foram realizadas no Campus I da Universidade Católica de Brasília, em salas de aula disponíveis no dia e horário escolhidos pelas entrevistadas, em ambiente que permitia a não interrupção por terceiros e com privacidade aos entrevistados.

A coleta das informações foi realizada em duas fases. No primeiro momento, as avós responderam a questionário no qual constavam os seguintes dados sócio-biográficos: identificação, número de netos e respectivas idades, corresidência e qual o neto de maior convívio e o motivo deste fato. A seguir, foram realizadas entrevistas semiestruturadas com as avós e, posteriormente, com o(s) neto(s).

Cada entrevista teve duração de cerca de 40 minutos, sendo abordados temas a respeito de avosidade, ou seja, da relação das avós com seus respectivos netos. Foi seguido um roteiro de questões nas entrevistas, a saber: o que pensa sobre ser avó; qual o significado de ser velha; o que sentiu quando se tornou avó pela primeira vez; quais as atividades realizadas em comum com os seus netos e entre elas qual mais gosta; quais as responsabilidades com os seus netos; se há perda de contato com os netos à medida que crescem; $\mathrm{e}$ características positivas e negativas de seus netos. Estas entrevistas foram gravadas e, posteriormente, transcritas integralmente.

A seguir, foram realizadas as entrevistas com os netos, utilizando-se os mesmos procedimentos realizados com as avós ${ }^{11}$. O roteiro dessas entrevistas foi o seguinte: quais as atividades realizadas com as avós e qual mais gostava; se já havia pensado como seria sua velhice; e se gostaria de ser igual à avó no futuro. 
A análise das respostas das avós foi feita através do software ALCEST (Análise Lexical por Conjunto de Segmentos de um Texto), que objetiva desvelar a informação essencial contida em um texto, através da classificação estatística de enunciados simples do corpus estudado, em função da distribuição das palavras dentro do enunciado, aprendendo as palavras que lhes são características ${ }^{12}$. Esse softwrare realizou automaticamente a análise quantitativa dos dados textuais obtidos, efetuando dois tipos de análise:Classificação Hierárquica Descendente $(\mathrm{CDH})$, a qual apresenta classes lexicais e suas oposições; e Análise Fatorial de Correspondência (AFC), que visualiza as oposições resultantes da $\mathrm{CDH}$. O software identificou no texto as Unidades de Contexto Elementar (UCE), agrupando-as em classes semânticas homogêneas, com conteúdo lexical específico e significado único.

Esse programa também forneceu uma relação entre as três classes encontradas, estabelecendo a proximidade de significado entre elas. Essa relação entre as classes, denominada " $R$ ", foi quantificada em valores que variaram de $\mathrm{O}$ a 1 , sendo, quanto mais próximo da unidade 1 maior a relação entre duas ou mais classes, ou seja, a consistência entre elas e, assim, o zero significando uma relação fraca ou nula.

Para análise das entrevistas realizadas com os netos, foram criadas categorias nas quais foram abordados determinados temas ${ }^{13}$. A realização desta análise através do software ALCESTE exigiria maior número de caracteres do que o encontrado no presente trabalho.
O estudo foi aprovado pelo Comitê de Ética da Universidade Católica de Brasília, de acordo com a Resolução no 196/96 do Ministério da Saúde ${ }^{11}$, registrado sob o ${ }^{\circ}$ CEP/UCB 048/2009. Os participantes da pesquisa assinaram o termo de consentimento livre e esclarecido.

\section{RESULTADO}

O conteúdo analisado pelo software, obtido das entrevistas com as avós, mostrou corpus com 7.132 palavras, sendo 1.361 formas distintas, tendo o programa aproveitado como significativo 63,3\% desse total.

A análise estatística identificou 16 unidades de contexto inicial (UCI), que formaram o corpus das entrevistas. A média de frequência das palavras foi de cinco vezes, sendo que 744 palavras apareceram uma única vez (rápax). Desse total, foram identificadas 129 UCEs, agrupadas em três classes distintas: classe 1 visão das avós; classe 2 - relação entre avós e netos; classe 3 - visão das idosas sobre a velhice.

A classe 1 foi formada com palavras fortemente ligadas entre si, de acordo com sua distribuição nas unidades onde o pensamento foi anunciado. As palavras dessa classe mais significativas foram avós e negativo, com valores de $x^{2}$ iguais a 20,57 e 14,14 , respectivamente. Dentre estas palavras, a mais frequente foi negativo, com $100,00 \%$ de frequência. A palavra menos significante foi todo, com valor de $x^{2}$ igual a 6,23 (Tabela 1). 
Tabela 1 - Descrição da Classe 1 "Visão das avós", nas entrevistas realizadas em Brasília, 2009. (Oliveira, AR. Brasília, DF, 2009).

\begin{tabular}{lcc}
\hline Palavras da Classe 1 & \multicolumn{1}{c}{$\mathrm{x}^{2}$} & Frequência (\%) \\
\hline avós & 20,57 & 67,74 \\
negativo & 14,14 & 100,00 \\
jeito & 9,93 & 100,00 \\
ponto & 9,93 & 100,00 \\
estudo & 9,93 & 100,00 \\
mundo & 9,93 & 100,00 \\
pai & 9,61 & 71,42 \\
porque & 9,51 & 59,26 \\
acho & 7,96 & 57,69 \\
falta & 7,86 & 100,00 \\
depende & 7,86 & 100,00 \\
assumo & 7,86 & 100,00 \\
filhos & 7,85 & 72,83 \\
netos & 7,25 & 59,09 \\
época & 6,67 & 83,33 \\
carinho & 6,23 & 75,00 \\
responsabilidade & 6,23 & 75,00 \\
crio & 6,23 & 75,00 \\
todo & 6,23 & 75,00 \\
\hline
\end{tabular}

$\mathrm{Na}$ classe 2, as palavras mais frequentemente encontradas foram ajudar e gostar, com valores de $x^{2}$ iguais a 13,05 e 12,20 , respectivamente. As palavras que apresentaram a maior frequência foram: televisão, posso e brincar, com valores de $x^{2}$ iguais a 11,44 para cada palavra. A palavra de menor significado foi ver, com valor de $\mathrm{x}^{2}$ igual a 6,96 e frequência de 99,99\% (Tabela 2 ). 
Tabela 2 - Descrição da Classe 2 "Relação entre avós e netos", nas entrevistas realizadas em Brasília, 2009. (Oliveira, AR. Brasília, DF, 2009)

\begin{tabular}{lcc}
\hline Principais palavras da Classe 2 & $\mathrm{x}^{2}$ & Frequência (\%) \\
\hline ajudar & 13,05 & 77,27 \\
gostar & 12,20 & 71,42 \\
televisão & 11,44 & 99,99 \\
posso & 11,44 & 99,99 \\
brincar & 11,44 & 99,99 \\
levo & 9,92 & 99,99 \\
fazer & 7,47 & 72,21 \\
escola & 5,57 & 85,71 \\
caminho & 5,51 & 99,99 \\
lavo & 5,51 & 99,99 \\
passear & 5,51 & 99,99 \\
tento & 5,51 & 99,99 \\
comida & 5,51 & 99,99 \\
apego & 5,51 & 99,99 \\
sou & 7,50 & 81,81 \\
ver & 6,96 & 99,99 \\
\hline
\end{tabular}

$\mathrm{Na}$ classe 3, as palavras mais significativas foram lembro e respeito, com $x^{2}$ igual a $17,77 \mathrm{e}$ frequência de 99,99 para cada palavra. As palavras de menor significância foram causa, velho, chamo e cidade, com valores de $x^{2}$ iguais a 6,45 e frequência de 74,99 para cada uma das palavras (Tabela 3 ). 
Tabela 3 - Descrição da Classe 3 "Visão da idosa sobre a velhice", nas entrevistas realizadas em Brasília, 2009. (Oliveira, AR. Brasília, DF, 2009).

\begin{tabular}{lcc}
\hline Palavras principais da classe 3 & $\mathrm{x}^{2}$ & Frequência $(\%)$ \\
\hline lembro & 17,77 & 99,99 \\
respeito & 17,77 & 99,99 \\
idosos & 16,83 & 85,71 \\
historia & 14,09 & 99,99 \\
experiência & 14,09 & 99,99 \\
vida & 13,37 & 74,99 \\
grande & 13,24 & 83,33 \\
ano & 10,74 & 57,14 \\
fila & 10,48 & 99,99 \\
chego & 9,76 & 79,99 \\
disse & 9,76 & 79,99 \\
pessoa & 8,08 & 53,85 \\
atividade & 6,97 & 66,67 \\
causa & 6,45 & 74,99 \\
velho & 6,45 & 74,99 \\
chamo & 6,45 & 74,99 \\
cidade & 6,45 & 74,99 \\
\hline & &
\end{tabular}

A figura 1 apresenta o quadro sintético dos resultados gerados pela análise do programa
ALCESTE, mostrando a relação entre as três classes encontradas. 


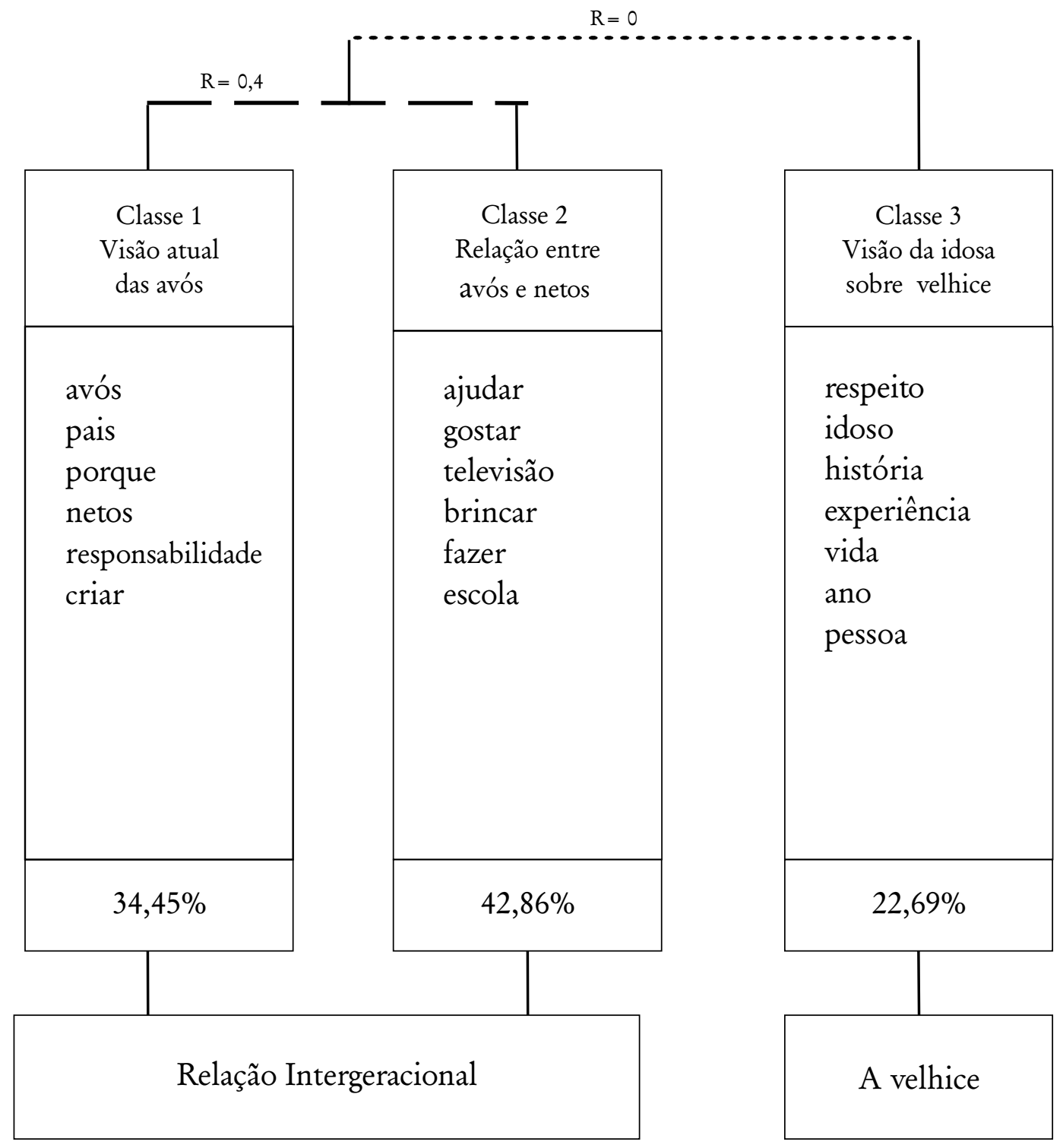

Figura 1 - Relação entre as três classes geradas no programa ALCESTE, em entrevistas realizadas em Brasília, DF. 2009.

A Figura 2 mostra uma forma representativa discurso coletivo utilizando a relação entre as atribuída para cada classe, reconstruindo o palavras, a frequência percentual com que apareceram e seu significado. 


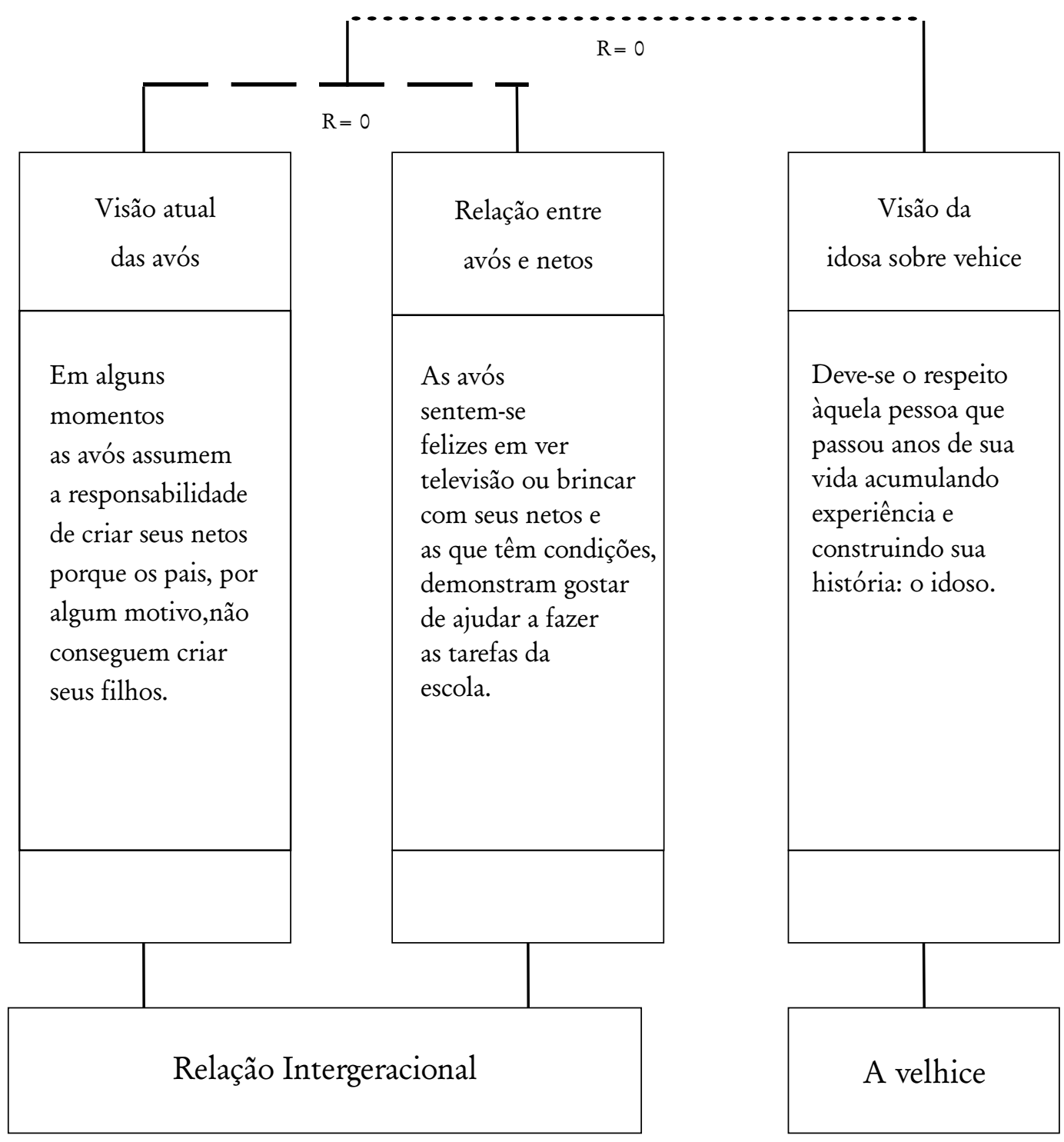

Figura 2 - Reconstrução do discurso coletivo utilizando-se o programa ALCESTE, em entrevistas realizadas em Brasília, DF. 2009.

Entre os 17 netos das avós entrevistadas, apenas oito deles, com idade igual ou superior a nove anos, aceitaram ser entrevistados. Os dados de gênero, faixa etária, se filho(a) do filho ou filha, se moravam com as avós e número total de netos estão mostrados no Quadro 1.
Verificou-se que $75 \%$ dos netos entrevistados eram do gênero feminino, sendo a faixa etária predominante de 11 a 12 anos (62\%). De todos os netos, $62 \%$ eram filhos da filha, sendo que $37 \%$ residiam com a respectiva avó (Quadro 1). 
Quadro 1- Dados dos oito netos entrevistados em Brasília,DF. 2009.

\begin{tabular}{|lcc|}
\hline Características & $N^{\circ}$ netos & Frequências (\%) \\
\hline Gênero & & 75 \\
\hline feminino & 06 & 25 \\
\hline masculino & 02 & \\
\hline Faixa etária & & - \\
\hline 6 a 8 anos & - & 37 \\
\hline 9 a 10 anos & 03 & 62 \\
\hline 11 a 12 anos & 05 & 37 \\
\hline Filho(a) do filho & 03 & 62 \\
\hline Filho(a) da filha & 05 & 37 \\
\hline Morava com a avó & 03 & 100 \\
\hline No total de netos & 08 & \\
\hline
\end{tabular}

$\mathrm{Na}$ análise das entrevistas realizadas com os netos, foram criadas categorias que revelaram benefícios, sentimentos e significados ${ }^{13}$, como mostrado no Quadro 2.

Quadro 2 - Categorias e subcategorias encontradas nas entrevistas dos oito netos, realizadas em Brasília, DF. 2009.

\begin{tabular}{|ll|}
\hline Categorias & Subcategorias \\
\hline Benefício & Diversão \\
\hline & Afeto \\
\hline Sentimento & Orgulho \\
\hline & Diferença \\
\hline Significado & Desconhecido \\
\hline & Previsível \\
\hline
\end{tabular}

A categoria beneficio pretende apresentar, dentro do universo pesquisado, as falas que mostram os efeitos positivos da relação entre avós e seus netos no período da infância. Compreende como subcategorias: diversão e afeto. Observa-se na subcategoria diversão que o neto ou neta apresentam alegria e satisfação quando realizam determinada atividade junto com sua avó, como destacado a seguir.

(...) "Eu acho que quando a gente tá na cozinha a gente se diverte mais, eu acho que essa é atividade que eu mais gosto de fazer com ela”. (neto N02)
(...) "Ah... eu gosto muito de ficar com ela em casa". (neto N03)

Evidenciam também a pura diversão pela companhia da avó, e o poder de compra levando à diversão, como a seguir.

(...) "Gosto de ir ao clube com ela". (neto N05)

(...) "Acho que o melhor é ir no supermercado com ela”. (neto N06)

(...) "Sair com ela e ir para Taguatinga pra comprar... bum...”. (neto N08) 
Na subcategoria afeto, o neto ou a neta valoriza o carinho dispensado pela avó, o qual reflete preferência e satisfação para ele, o que caracteriza o benefício, como a seguir.

(...) "Como ela é diferente, a gente vai mais na casa da outra avó, as vezes é melhor porque a gente recebe mais carinho, sei lá, não tem outros pra ficar preferindo". (neto N02)

A categoria sentimento mostra a forma de expressão da relação entre avós e seus netos na perspectiva dos netos. É dividida nas subcategorias orgulho e diferença. Na subcategoria orgulho, há tentativa de demonstrar as qualidades pessoais $\mathrm{da}$ respectiva avó, ocorrendo demonstração de sentimento positivo, como a seguir.

(...) 'Ela é mesmo uma vó nota 20!”. (neto N03)

(...) "Sim, pois mesmo com netos e ficando velha, ela tem um grande coração. Não mudaria nada". (neto N05)

(...) 'É, gostaria de ser igual a minha avó". (neto N06)

(...) "Claro! Porque ela tem uma coisa assim que é incrivel.Ela consegue atrair as crianças, fazerem elas felizes. Ela faz de um modo que eu não entendo, até já pedi a receita”. (neto No7)

Na subcategoria diferença, há demonstração de formas diferentes da relação entre as avós e seus netos, ocorrendo sentimento de inferioridade do neto em relação aos outros netos, devido à diferença demonstrada pela avó paterna e, ainda, à comparação com o tratamento dispensado pela avó materna, como a seguir.

(...) 'No Natal, os presentes que ela dá pra eles são bem superiores, parecendo que ela prefere os outros netos. Já a minha avó Maria não faz isso". (neto $\mathrm{No2}$ )

A categoria significado da velhice exprime o que é ser velho ou velha para os netos, sendo dividida nas subcategorias desconbecido e previsto. $\mathrm{Na}$ subcategoria desconbecido, entende-se que o neto ou a neta não encontra características para expressar o termo velhice, havendo a sensação de medo do desconhecido, como a seguir.
(...) "Eu acho que vai ser um pouco diferente da realidade que os velhos têm hoje, porque assim, a tecnologia vai evoluir bastante, então vai ser muito diferente. Vai ser bem diferente mesmo, eu acho". (neto N01)

(...) "Eu já falei assim com meus amigos, eu acho estranho a gente falar. Vai ser estranho quando ficar velho. A gente se não imagina avô jogando vídeogame”. (neto N02)

\section{(...) "Não quero chegar lá tão cedo". (neto N05)}

$\mathrm{Na}$ subcategoria previsto, ao contrário da anterior, entende-se que o neto ou a neta apresenta conhecimento sobre a sua velhice, sugerindo que essa velhice não seja assustadora para eles, como a seguir.

(...) "Tápensei em ficar velha. Acho que vou serigual a ela". (neto N03)

(...) "Ah... vou ser igual a ela, né". (neto N06)

\section{DISCUSSÃO}

De acordo com os dados obtidos nas classes 1 e 2, o grau de satisfação das avós na relação com seus netos, que se encontravam na faixa etária de seis a 12 anos, foi alto. As avós entrevistadas possuíam intenso vínculo com seus netos, ficando visível a felicidade que essa relação transmitia a essas avós. Este achado é equivalente aos encontrados na literatura ${ }^{14}$.

A responsabilidade, o carinho e o amor que as avós demonstraram foram construídos a partir da convivência em suas famílias, da criação de seus filhos e do acompanhamento das gestações de suas filhas até o nascimento dos respectivos netos ${ }^{15}$. A partir de então, a frequência de contato com o neto passou a ser fator importante no aumento dos efeitos positivos dessa relação, pois quanto maior o contato avó-neto, maior o número e o tempo de atividades executadas em conjunto, o que possibilita estabelecer uma relação mais forte entre os dois sujeitos.

De acordo com os resultados obtidos na classe 1, quando os filhos, por algum motivo, não 
assumem seus próprios filhos, as avós incorporam a responsabilidade materna e se consideram as principais substitutas para essa atribuição. Os sentimentos das avós direcionados aos netos foram calorosos, pois as mesmas sentiram-se satisfeitas em apoiar, proteger e ensinar seus netos ${ }^{16}$.

A relação que as avós mantêm com seus netos vai se modificando à medida que os netos crescem. De acordo com os dados obtidos na classe 2 , as avós entrevistadas mantiveram atividades como brincar, ver televisão e ajudar nas tarefas da escola de forma satisfatória para as mesmas, independentemente da faixa etária dos netos. Contar histórias infantis não apareceu como atividade importante, o que ocorreu nas histórias de vida, mostradas como experiências para os netos ${ }^{1}$.

$\mathrm{Na}$ categoria sentimento, houve demonstração de diferença na relação entre a avó materna e a avó paterna na perspectiva do neto, sugerindo uma relação mais próxima com a primeira. Considerando os resultados obtidos nas classes 1 e 2, há sugestão de que a relação das avós com os netos da linha materna é mais íntima do que com a da linha paterna, devido à proximidade da avó com sua filha, o que também confirma os dados da literatura ${ }^{1}$. As avós da linha materna tendem a se relacionar de forma mais íntima com seus netos e se tornarem mais frequentemente cuidadoras substitutas dos pais do que as da linha paterna. Assim, as avós maternas estão mais próximas à família e, consequentemente, aos netos, devido à confiança que as mães depositam nelas ${ }^{15}$. O papel da linha familiar como diferenciador das percepções dos netos a respeito da relação com suas avós é importante. As avós da linha materna são as verdadeiras figuras significativas para seus netos até a adolescência ${ }^{3}$.

No estudo atual, de acordo com os dados obtidos na classe 2, as avós mantiveram a responsabilidade em levar seus netos à escola, mesmo com os netos na faixa etária de nove a 12 anos, pois a palavra afastamento ou distanciamento não obteve frequência significativa na análise realizada pelo ALCESTE. Este dado está em desacordo com a literatura, que mostra a responsabilidade das avós nessa atividade declinando consideravelmente nessa faixa etária dos netos, pois os mesmos adquirem progressivamente maior autonomia ${ }^{14}$.

As avós entrevistadas mantinham uma relação emocional de proximidade com seus netos, pois educavam, decidiam e os protegiam da maneira que podiam, sentindo-se satisfeitas com isso. Há sugestão de que o objetivo desse esforço seja a união da família e a evolução das futuras gerações. É provável uma tendência de que a mulher siga no papel de cuidadora de crianças, como demonstram os dados das classes 1 e 2. De modo geral, afeto e cuidado é dispensado pela maioria das avós.

$\mathrm{Na}$ dados da classe 3 sugerem uma solicitação de respeito por parte das avós idosas à sociedade na qual estão inseridas. As avós descrevem o idoso como uma pessoa que construiu sua história através da experiência acumulada e que, por isso, merece respeito.

$\mathrm{Na}$ pesquisa atual, $62 \%$ dos netos eram filhos da filha, sendo que $37 \%$ residiam com a respectiva avó. No Brasil, 64,7\% dos idosos moram com filhos e/ou outros parentes no mesmo domicílio ${ }^{17}$.

Na visão dos netos, de acordo com a categoria significado da velhice, o envelhecimento pode causar medo, mas também pode ser previsível e não assustador. $\mathrm{O}$ envelhecimento é um processo fisiológico, gradual, previsível e inevitável, próprio dos seres vivos, o qual envolve evolução e maturação, sendo determinado geneticamente e modulado ambientalmente ${ }^{18}$. As sociedades tradicionais possuem características específicas, sendo a prevalência da consciência coletiva em relação à consciência individual o seu traço essencial. $\mathrm{O}$ indivíduo não se pertence, mas pertence ao grupo, o qual se apresenta na forma da família, da religião e da tradição ${ }^{19}$.

$\mathrm{Na}$ realidade brasileira, há necessidade de tornar o homem crítico e consciente em relação ao significado da velhice e do valor cultural dos idosos. A imagem do ser velho hoje, numa 
sociedade utilitária, é permeada por mitos e preconceitos que são incorporados e transmitidos por gerações. As crianças também exprimem esses preconceitos e mitos quando se trata da velhice ${ }^{20}$. Sendo a infância período da vida de significativa importância no processo de crescimento e desenvolvimento do ser humano, na qual a educação deve promover a autonomia através das experiências e vivências das crianças, refletindo e criando responsabilidades e fornecendo liberdade de escolhas, é essencial que aprendam a valorizar os idosos ${ }^{20}$.

$\mathrm{Na}$ perspectiva dos netos, a categoria benefício revelou a satisfação e o afeto sentido com o convívio com suas avós, o que demonstra a bidirecionalidade dessa relação. Assim, confirmase o importante papel que as avós desempenham na vida dos netos.

Avosidade é tema ainda pouco estudado. Com as mudanças rápidas que ocorrem nas famílias na contemporalidade, os avós estão ocupando novos papéis. Portanto, novas pesquisas devem ser feitas, com caráter horizontalizado ou verticalizado, fazendo-se novas perguntas. Como inúmeros fatores determinam a configuração das relações entre avós e netos, deve-se questionar também sobre: a idade em que isso ocorreu, a incidência de outros netos, a história de relacionamento com os filhos e seus parceiros, a história de relacionamento com o próprio parceiro, o entendimento do envelhecimento pelo próprio avô/avó e determinações culturais, entre outros. Além disso, o papel do avô difere do da avó, tornando necessárias pesquisas focando essas diferenças.

O estudo atual revelou dados para a avaliação da relação intergeracional entre avós e netos, propiciando que as diferenças observadas nos comportamentos e nas atitudes abram caminho para novos estudos sobre avosidade. Compreender que mesmo durante a vida adulta ainda passaremos por muitas transformações, incluindo a avosidade, é o primeiro passo na construção de relações intergeracionais satisfatórias. Assim, espera-se que esta pesquisa seja uma semente jogada em terra fértil, que fará germinar novas plantas, pois avosidade é tema inesgotável.

\section{REFERÊNCIAS}

1. Aratangy LR, Posternnak L. Livro dos avós: na casa dos avós é sempre domingo? SãoPaulo: Artemeios, 2006.

2. Paz SF, et al. Envelhecer com cidadania: quem sabe um dia? Rio de Janeiro: CBCISS; ANGRio, jul. 2000.

3. Triado C, et al. El rol y la importancia de los abuelos para sus nietos adolescentes. Anuario 2000, v.31, n.2, p.107-118.

4. Dias CM, Silva MA. Os avós: uma revisão da literatura nas três últimas décadas. Rio de janeiro: NAU Editora, 1999.

5. Camarano A, et al. Famílias: espaço e compartilhamento de recursos e vulnerabilidades. Rio de Janeiro: IPEA, 2004.

6. Castro OP. Velhice que idade é esta? Uma construção psicossocial do envelhecimento. Porto Alegre: Síntese, 1998.

7. Dias CM, Silva MA. Os avós na perspectiva de jovens universitários. Psicologia em Estudo 2003, v.8, n esp., p.55-62.
8. Gusmão NM. Infância e Velhice. Pesquisa de idéias. Campinas, SP: Alínea, 2003.

9. Araújo MR, Dias CM. Papel dos avós: apoio oferecido aos netos antes e após situações de separação/divórcio dos pais. Estudos de Psicologia 2002, v.7, n.1, p.91-101.

10. Redler P. Abuelidade. Nás Allá de La Paternidade. Argentina: Ed. Legasa,1986.

11. Brasil. Ministério da Saúde. Conselho Nacional de Saúde, Comitê Nacional de Ética em Pesquisa em Seres Humanos. Resolução 196 de outubro de 1996: diretrizes e normas regulamentadoras de pesquisas envolvendo seres humanos. Brasília, DF, 1996.

12. Reinert M. Alceste. Une Methodlogie d'analyse des donnes textuelles et une application: aurelia de gerard de nerval. Bulletin de Methodologie Socioligique 1990, v. 1, n.26, p.24-54.

13. Guedes, HM. Idoso e arte: uma relação possível com a auto-imagem? Dissertação de Mestrado em Gerontologia, Universidade de Brasília, Brasília, 2007. 
14. Osuna MJ. Relaciones familiares en la vez: vinculos de los abuelos y de las abuelas con sus nietos y nietas en la infancia. Revista Multidisciplinar Gerontologia 2006, v16, n1,p.16-25.

15. Leite I. Gênero, família e representação social da velhice. Londrina: Eduel, 2004.

16. Beauvoir S. A velhice. Rio de janeiro: Nova Fronteira, 1990.

17. Instituto Brasileiro de Geografia e Estatística (IBGE). Perfil dos Idosos Responsáveis pelos domicílios no Brasil-2000. Disponível em < http:// www.ibge.gov.br/ibgeteen/datas/idoso/ perfil_idosos.html >. Acesso em 25 fev. 2007, 8:00:00.
18. Botelho MA. Idade Avançada - características biológicas e multimorbilidade. Revista Portuguesa Clinica Geral, Lisboa 2007, v. 23, p.191-195.

19. Cruz IBM, Gomes L (Orgs.) Envelhecimento dos povos tradicionais brasileiros: perspectivas e desafios. Brasília: Universa, 2008.

20. Mazutti C, Scortegagna HM. Velhice e envelhecimento humano: concepções de préescolares do município de Tapejara - RS. Revista Brasileira de Ciências do Envelhecimento Humano 2006, jul./dez.,v.1, n.1, p.101-112. 